\title{
Iron entangled
}

\author{
Iron is an essential fuel for life in the oceans. The influence of this element on biogeochemistry - and \\ nitrogen cycling in particular — varies across environments and time.
}

Iron is a vital micronutrient required for photosynthesis and other metabolic reactions. The amount of iron that cells need to thrive is tiny compared to carbon, nitrogen and phosphorus, but in areas of the oceans where these elements are plentiful, a lack of iron limits the amount of primary productivity. However, the marine iron cycle has looked very different over Earth's history, for instance when anoxic or low-oxygen conditions altered the behaviour of this metal. A web focus published online with this month's issue (http://go.nature.com/2lOFmDb) delves into marine iron cycling through time.

Iron is supplied to the ocean from above and below. The sea surface receives iron through runoff from land and dust deposition, and sediment biogeochemical reactions and hydrothermal venting supply the element at the base of the ocean. Changes to this influx have been linked to variations in ocean productivity and carbon sequestration. In particular, enhanced dust delivery in a dry and windy climate is widely invoked to explain high productivity in the Subantarctic Southern Ocean during glacial periods (Martinez-Garcia, A. et al. Science 343, 1347-1350; 2014).

Dust also fuels primary productivity in the modern oceans. On page 189, Pabortsava et al. show that the higher rate of carbon sequestration found in the North Atlantic subtropical gyre relative to the South Atlantic gyre is the result of Saharan dust deposition.

The mechanism, however, is different to that found in the nutrient-rich Southern Ocean, where - once iron is available organisms can quickly make use of the abundant carbon, nitrogen and phosphorus already present in the surface waters. In the low-nutrient waters of the North Atlantic subtropical gyre, the iron carried by the dust stimulates nitrogen fixation, providing the raw materials needed for further productivity.

Unlike dust deposition, which can vary markedly even over short timescales, the amount of iron supplied by hydrothermal activity is relatively constant over millennial timescales. Although hydrothermal activity occurs in a limited set of locations, the plumes of dissolved metals generated at these sites can persist over thousands of kilometres. On page 195, Fitzsimmons and colleagues show that particulate iron also persists in

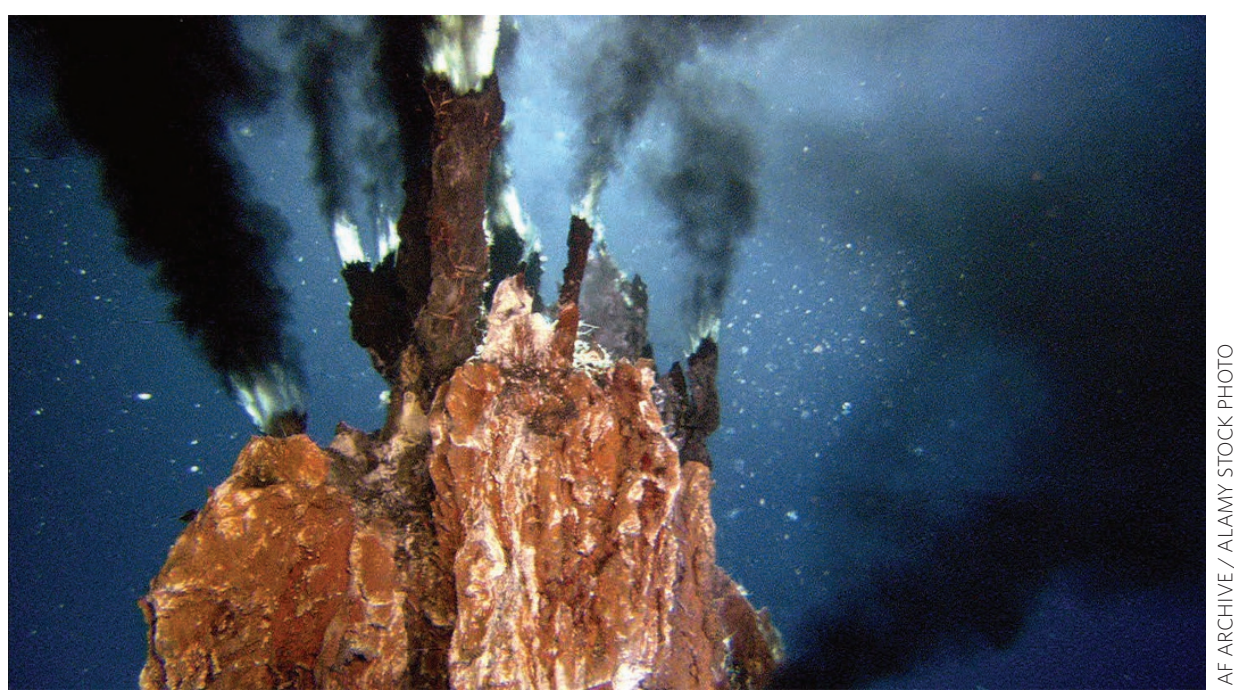

these plumes over long distances. Moreover, iron exchange between the dissolved and particulate form appears to be continuous, and reversible as the particles sink. These particles generally take the form of Fe(III) oxyhydroxides associated with organic matter, meaning that the iron in these minerals takes the form of $\mathrm{Fe}^{3+}$.

The occurrence of the more oxidized form of iron in these particles is consistent with the availability of oxygen in much of the deeper ocean. However, in the deep oceans that characterized much of Earth's past, oxygen was in short supply, presumably favouring the presence of a more reduced form of iron, $\mathrm{Fe}^{2+}$. Indeed, anoxic and iron-rich (ferruginous) deep ocean conditions persisted for much of the Precambrian. The wealth of iron in the Precambrian oceans is evident in the banded iron formations that were deposited intermittently between 2.4 and 1.8 billion years ago. Despite forming in anoxic deep waters, the iron in these chemical sediments takes the form of both $\mathrm{Fe}^{2+}$ and $\mathrm{Fe}^{3+}$.

Photochemical reactions in the sunlit ocean surface, microbial cycling and - later in time - reactions with growing amounts of free oxygen have been invoked to explain this mix. Halevy and co-authors (Nat. Geosci. 10, 135-139; 2017) demonstrated that when the supply of $\mathrm{Fe}^{3+}$ provided by these reactions is high enough, green rust readily precipitates under conditions thought to be analogous to the Precambrian oceans. They calculate that green rust would have transported iron to the sediments, which then served as a substantial sink for $\mathrm{Fe}^{3+}$.

The persistence of $\mathrm{Fe}^{2+}$ in the Precambrian oceans may have had an effect on overall nutrient cycling. In anoxic systems with relatively low iron abundance, microbial denitrification removes biologically available nitrogen from the water column by converting nitrate to $\mathrm{N}_{2}$. However, as Michiels et al. show on page 217, in a modern ferruginous lake, the presence of $\mathrm{Fe}^{2+}$ promotes an additional microbial reaction that converts nitrate to ammonium, which is still biologically available. Thus the ancient oceans may not have been as nitrogen limited as previously thought.

Ferruginous conditions will not be making a comeback in the modern oceans, but studying iron cycling across a wide range of conditions can help inform our understanding of how the iron cycle might change in the future; potential changes in abiotic reactions due to ocean warming, deoxygenation and acidification are particularly poorly constrained (Hutchins, D. A. \& Boyd, P. W. Nat. Clim. Change 6, 1072-1079; 2016). Changes in where dust is generated and and the extent of seafloor anoxia will all alter the iron budget - and the productivity that the iron fuels - in complex ways. The works presented in our focus suggest that changes in iron availability will impact other nutrient budgets as well, including nitrogen. transported, the upwelling of subsurface iron 